\title{
Have the IHS Guidelines for controlled trials of acute treatment of migraine attacks been followed? Laying the ground for the 4th edition
}

Cephalalgia

2020, Vol. 40(8) 778-787

(C) International Headache Society 2020

Article reuse guidelines:

sagepub.com/journals-permissions DOI: $10.1177 / 0333102420906843$

journals.sagepub.com/home/cep

@SAGE

\author{
Alicia Alpuente ${ }^{1,2} \odot$, Cristina Tassorelli, ${ }^{3,4} \odot$, \\ Hans-Christoph Diener ${ }^{5}$, Stephen D Silberstein ${ }^{6}{ }^{6}$ \\ and Patricia Pozo-Rosich ${ }^{1,2}$
}

\begin{abstract}
Background: The International Headache Society (IHS) has published four editions of Guidelines for acute clinical trials in migraine in the past 28 years. This continuous update process has been driven by the increasing amount of scientific data in the field of migraine and by the need to continuously improve the quality of trials.

Objectives: To illustrate: i) the results of the analysis on the adherence of published trials to the $3 \mathrm{rd}$ edition published in 2012, in order to identify the critical areas that needed to be addressed in the 4th edition and ii) the changes introduced in this latter edition for improving adherence and methodology robustness.

Methods: We searched and reviewed all controlled trials on acute treatment of migraine published in the period 20I22018 and we assessed their adherence to the 3rd edition of the IHS Guidelines using a score system based on the most important recommendations. Afterwards, we compared the two editions of the Guidelines and assessed the changes between them.

Results: We included data from 24 controlled clinical trials. Most trials had a randomized double-blind controlled (RDB) design, while a minority (16.7\%) were non-randomized double-blind trials. Less than half (44.6\%) of the RDB trials used the recommended "pain-free at 2 hours" endpoint as the primary efficacy measure. Trial design and evaluation of results were the areas that diverged the most from the recommendations.

Conclusion: Adherence to IHS guidelines for clinical trials has been suboptimal so far. The new edition has been adapted and optimized to facilitate uptake and strengthen the quality of evidence.
\end{abstract}

\section{Keywords}

Migraine, episodic migraine, guidelines, randomized clinical trials, acute treatment, headache

Date received: 3 October 2019; revised: 16 December 2019; II January 2020; accepted: 20 January 2020

\section{Introduction}

Since their first appearance in 1991 (1), the Guidelines for controlled trials of acute treatment of migraine attacks of the International Headache Society (IHS) were intended as a tool to improve the quality of clinical research. Their publication grossly corresponded with the publication of the first controlled studies on sumatriptan and the Guidelines were instrumental in providing a large and reliable body of evidence on the efficacy of triptans. Building on the experience accumulated with triptans, the document underwent revision in 2000 (2). In the subsequent years, the growing interest

\footnotetext{
'Headache Unit, Neurology Department, Vall d'Hebron University Hospital, Barcelona, Spain

${ }^{2}$ Headache and Neurological Pain Research Group, VHIR, Universitat Autonoma of Barcelona, Barcelona, Spain

${ }^{3}$ Headache Science Center, IRCCS Mondino Foundation, Pavia, Italy

${ }^{4}$ Department of Brain and Behavioral Sciences, University of Pavia, Pavia, Italy

${ }^{5}$ Medical Faculty of the University Duisburg-Essen, Essen, Germany

${ }^{6}$ Department of Neurology, Thomas Jefferson University Hospital,

Philadelphia, PA, USA
}

\section{Corresponding author:}

Patricia Pozo-Rosich, Headache Unit, Neurology Department, Hospital Universitari Vall d'Hebron, Barcelona, Spain. I19-129 Passeig de la Vall d'Hebron, 08035 Barcelona, Spain.

Email: ppozo@vhebron.net 
in the migraine field, the new drugs developed and the exponential growth in clinical research led to a further update of the Guidelines in 2012 (3). The Food and Drug Administration (FDA) and the Center for Drug Evaluation and Research (CDER) referred to these Guidelines to prepare their own, published in February 2018 (4).

Evaluating the adherence to the IHS Guidelines is important because, on one hand, it provides objective information on the quality of trials and allows selection of the studies that are suitable (or not) for data comparison through meta-analyses, while allowing, on the other, the identification of problematic areas that may benefit from further improvement, thus promoting the development of new strategies for ensuring high-quality standards in headache treatment. Guidelines need to be as evidence-based as possible, reliable and applicable. To this end, it is extremely important to evaluate a posteriori whether published guidelines have been followed. In 2010, Hougaard and Tfelt-Hansen analyzed the adherence to the 2000 IHS guidelines for migraine drug trials (5). Their assessment showed that the recommendations regarding the adoption of randomized, double-blind and placebo-controlled designs were followed in $67 \%$ of the clinical studies, but only $31 \%$ of these randomized double-blind (RDB) trials applied the recommended "pain-free at 2 hours" as their primary endpoint. This analysis led to underscoring the importance of "pain-free at 2 hours" as a primary endpoint in the updated IHS guidelines published in 2012.

Since then and until now, several clinical trials for the acute treatment of migraine attacks have been carried out with different substances and preparations.

The objective of the present paper was to analyze adherence of the trials on the acute treatment of migraine published since the appearance of the 3rd edition of the IHS Guidelines (2012) in order to identify and evaluate the critical areas that needed to be addressed in the 4th edition, recently published (12). We are also presenting a comparative analysis of the changes that have been introduced in the 4 th edition to favor adherence to guidelines and robustness of trial methodology.

\section{Methods}

\section{Search methods}

In evaluating the adherence to the 3 rd edition of the IHS Guidelines, we searched available databases for the papers published from 1 January 2012 to 31 August 2018. Pubmed was searched using the term "acute migraine attack treatment". Clinicaltrials.gov was searched using the string words "acute migraine" and with the following criteria: Study type: Interventional studies; age group: Adult (18-64) and older adult
(65+). Review articles from Cochrane Central Register of Controlled Trials (CENTRAL) were used to search for clinical trials citations using the words "acute migraine".

\section{Eligibility}

To evaluate the adherence, studies were required to be prospective controlled trials of pharmacological interventions for the acute treatment of episodic migraine (EM) with or without aura.

Exclusion criteria were:

- Trials on pediatric and adolescent subjects;

- Studies of non-pharmacological interventions;

- Studies focusing solely on pharmacokinetics and/or pharmacodynamics;

- Studies focusing solely on safety and tolerability;

- Studies reporting only non-clinical outcome measures;

- Study designed and/or conducted before 2012.

Titles and abstracts of studies identified by the literature search were screened for eligibility. Papers that could not be included or excluded with certainty on the basis of the information contained in the title and/or the abstract were evaluated in full for screening.

\section{Data extraction and analysis}

We collected and analyzed trials focusing exclusively on the acute treatment of migraine. In order to ensure consistency with the assessment of adherence to the 2nd edition of the IHS guidelines performed by Hougaard and Tfelt-Hansen, we adopted the same scoring method proposed by these authors (5), also applied more recently by Deen et al. (6) More specifically, we developed a scoring system based on eight essential recommendations of the 2012 guidelines (Table 1). For each recommendation taken into consideration, we assigned one point when it was correctly followed in the trial and 0 points when it was not considered, partially or in full. The final score therefore ranged from a minimum of 0 to a maximum of 8 . The scoring methodology is shown in Table 1.

\section{Results}

\section{Data collection}

The search was performed in October 2018. We retrieved 204 items in Pubmed, 54 in Clinicaltrials.gov and 28 in CENTRAL. Forty-three papers were excluded because they were irretrievable. We therefore revised the remaining 243 titles and abstracts. 
Table I. Scoring system adopted for evaluating acute clinical trials in migraine.

\begin{tabular}{|c|c|}
\hline Selection of patients & Yes/No \\
\hline $\begin{array}{l}\text { - Do the diagnostic criteria conform to } \\
\text { those of the IHS Classification? }\end{array}$ & $(+\mathrm{l} /+0)$ \\
\hline \multicolumn{2}{|l|}{ Trial design } \\
\hline - Is the trial double blind? & $(+1 /+0)$ \\
\hline - Is the trial placebo-controlled? & $(+1 /+0)$ \\
\hline $\begin{array}{l}\text { - Were the trial participants randomized at } \\
\text { entry to the trial? }\end{array}$ & $(+I /+0)$ \\
\hline \multicolumn{2}{|l|}{ Evaluation of results } \\
\hline \multicolumn{2}{|l|}{ IHS recommended } \\
\hline $\begin{array}{l}\text { Was pain-free at } 2 \text { hours used as the } \\
\text { primary measure of efficacy? }\end{array}$ & $(+\mathrm{I} /+0)$ \\
\hline $\begin{array}{l}\text { - Is } 48-\mathrm{h} \text { sustained pain-free (percentage of } \\
\text { patients pain-free within } 2 \text { hours with no } \\
\text { use of rescue medication or relapse time } \\
\text { within } 48 \mathrm{~h} \text { ) used as a measure of efficacy? }\end{array}$ & $(+\mathrm{I} /+0)$ \\
\hline $\begin{array}{l}\text { - Is headache relief (percentage of patients } \\
\text { with a decrease in headache from severe or } \\
\text { moderate to none or mild within } 2 \text { hours } \\
\text { before any rescue medication) used as a } \\
\text { measure of efficacy? }\end{array}$ & $(+I /+0)$ \\
\hline
\end{tabular}

- Is the statistical analysis conducted according to the principle of intention-to-treat?

Others (considered for discussion, but not for scoring)

- Is time to meaningful relief used as a secondary measure of efficacy?

- Is speed of action used as an efficacy measure?

- Is 24-h sustained pain-free (percentage of patients pain-free within 2 hours with no use of rescue medication or relapse within $24 \mathrm{~h}$ ) used as a measure of efficacy?

- Is the percentage of patients taking rescue medication $2 \mathrm{~h}$ (or earlier if the time point for the primary outcome measure is specified at a time earlier than 2 hours) used as a secondary efficacy measure?

After deleting duplicates and eliminating the papers that did not satisfy the eligibility criteria or presented one or more of the exclusion criteria, only 24 out of the 243 selected papers resulted in being eligible for further evaluation (13-36) (Figure 1, flow diagram).

\section{Evaluation of trials}

Most trials had an RDB design, while a minority $(16.7 \%)$ were non-randomized double-blind trials. The mean score of the RBD trials was 4.6 (range 2-7), while the mean score of all 24 trials was 4.1

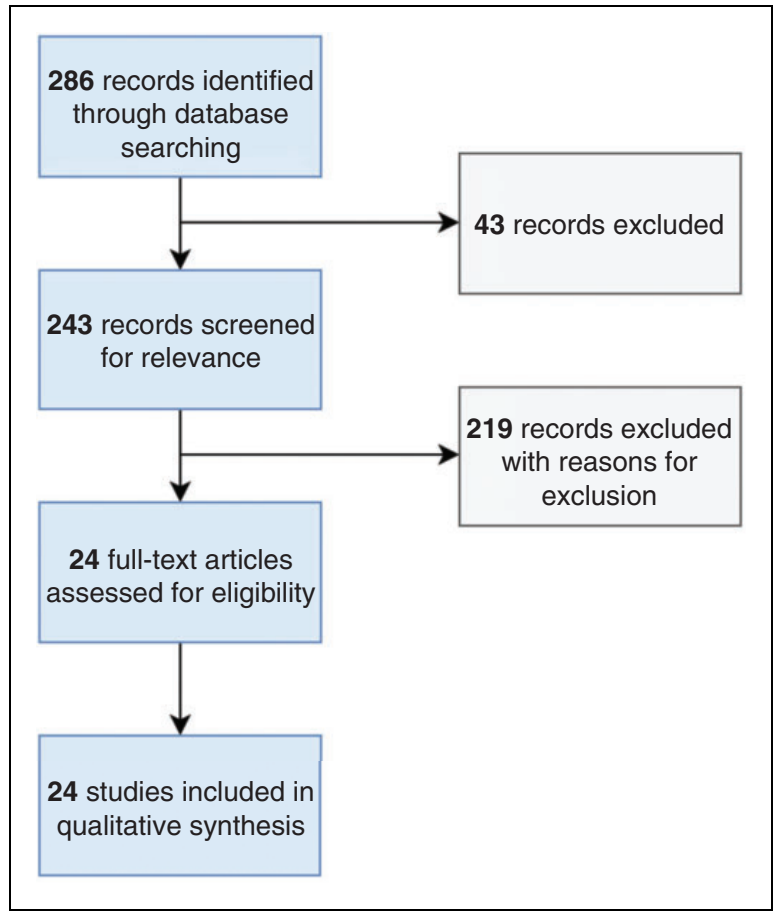

Figure I. Data collection flow diagram.

(range 1-7) (Table 2). Most studies used the IHS diagnostic criteria $(87.5 \%)$ (Table 3$)$. The mean number of treated subjects per trial was 188.25 (range 15-885). Nearly half of the trials $(45.8 \%)$ were carried out in the US and $25 \%$ in Europe. Most studies $(75 \%)$ were performed within a neurological setting, while the rest were carried out in the emergency room, led by general practitioners.

The recommended "pain-free at 2 hours" endpoint was considered as the primary efficacy measure in nearly $45 \%$ of RDB trials. "Headache relief" as the recommended secondary efficacy measure was used only in $33.3 \%$ of the reviewed RDB trials and "sustained pain-free" as the recommended secondary efficacy measure was used in six trials $(25 \%)$, while a modified and less rigorous version of this efficacy measure (headache relief at $24 \mathrm{~h}$, instead of $48 \mathrm{~h}$ ) was used in nine RDB trials.

Compliance with other important sections of the IHS recommendations was low in several studies. For example, 13 trials (54\%) did not use the placebo control and the vast majority of trials $(22 ; 92 \%)$ failed to apply the intention-to-treat analysis.

\section{Changes introduced in the 4th edition of the Guidelines (Table 4)}

Selection of patients. No substantial changes were introduced in this section, and both guidelines underscore 
Table 2. Results of the evaluation for acute treatment clinical trials in migraine.

\begin{tabular}{lc}
\hline $\begin{array}{l}\text { Mean score of randomized } \\
\text { double-blind trials }\end{array}$ & 4.6 (range 2-7) \\
Mean score of all reviewed trials & 4.1 (range I-7) \\
$\begin{array}{l}\text { Percentage of non- randomized } \\
\text { double-blind trials }\end{array}$ & $16.7 \%$ (4 of 24) \\
Percentage of randomized & \\
double-blind trials using the & $44.7 \%$ (I0 of 24) \\
recommended primary effi- & \\
cacy measure & \\
Percentage of randomized & \\
double-blind trials that were \\
placebo-controlled
\end{tabular}

the importance of adherence to the diagnostic criteria of the most updated version of the ICHD (7).

Trial design. The importance of the comparison with placebo is emphasized in this new edition due to the wide ranges of placebo responses reported in the various trials. Block randomization is added to reinforce the double-blind efficacy and the variables that demonstrated impact on the primary study outcome should be stratified. The intention-to treat analysis is mandatory when the primary outcome is a variable that measures a change from baseline to the end of the study or another given time. As regards the administration time of the drug under investigation, in general it is advisable that it be taken when the migraine head pain has at

Table 3. Compliance of clinical trials published between 2012 and 2018.

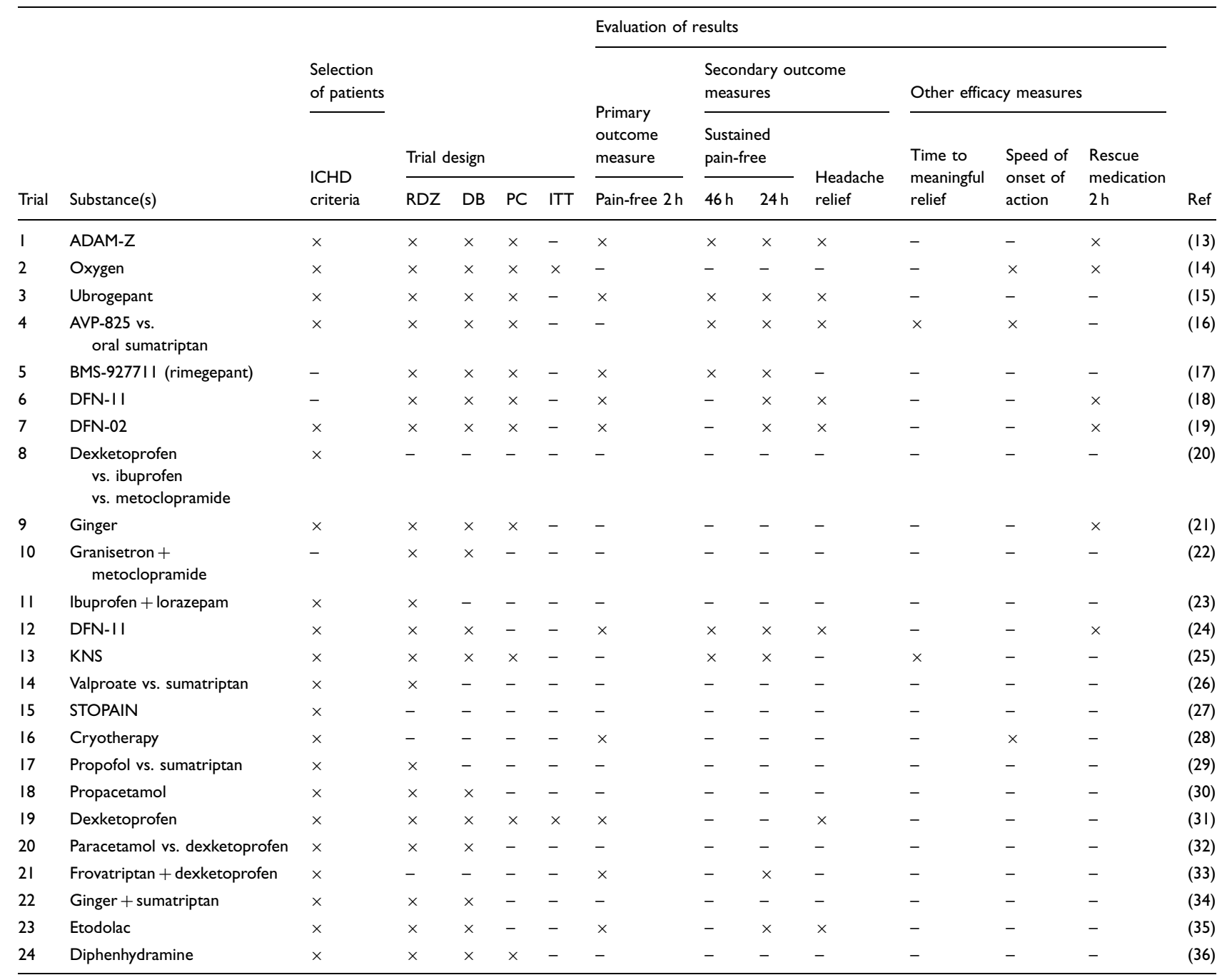


Table 4. Similarities and differences in the two editions of the guidelines for controlled trials of drugs in migraine.

\begin{tabular}{|c|c|c|}
\hline & 2012 & 2018 \\
\hline \multicolumn{3}{|l|}{ Selection of patients } \\
\hline Migraine definition & ICHD-II & ICHD-III \\
\hline Non-target headaches & $\begin{array}{l}\text { Permitted if well recognized by the } \\
\text { patients }\end{array}$ & Confirmed \\
\hline Frequency of attacks & $\begin{array}{l}\text { Migraine attacks } \mathrm{I}-6 / \text { month, other } \\
\text { (including interval headaches }<6 \text { days } \\
\text { per month }>\text { I years) }\end{array}$ & Confirmed \\
\hline Duration of disease & $\begin{array}{l}3 \text { months retrospective or I-month } \\
\text { prospective recording }\end{array}$ & Confirmed \\
\hline Age at onset & $<50$ years & Confirmed \\
\hline Age at entry & $18-65$ years & Confirmed \\
\hline Gender & Both female and male patients & Confirmed \\
\hline Concomitant drug use & $\begin{array}{l}\text { Not allowed in early phase studies, } \\
\text { permitted if specified in late trials }\end{array}$ & Confirmed \\
\hline \multicolumn{3}{|l|}{ Trial design } \\
\hline Blinding & Recommended & Confirmed \\
\hline Placebo control & Recommended & $\begin{array}{l}\text { No change in the recommendation, but the } \\
\text { comment underscores the importance of } \\
\text { mitigating placebo effect }\end{array}$ \\
\hline Parallel-group/crossover & Both designs acceptable & Parallel-group preferred \\
\hline Randomization & Recommended & Crucial, block randomization is useful \\
\hline Stratification & Not recommended in outpatient trials & $\begin{array}{l}\text { Recommended for variables that demon- } \\
\text { strated impact on the primary study out- } \\
\text { come, e.g. gender stratification }\end{array}$ \\
\hline Intention to treat (ITT) & Recommended & $\begin{array}{l}\text { Mandatory when the primary outcome is a } \\
\text { variable that measures a change from } \\
\text { baseline to the end of the study. If the pri- } \\
\text { mary outcome is the rate of change, only } \\
\text { patients who has received a single dose can } \\
\text { be included. }\end{array}$ \\
\hline Dose-response curve & Should be defined in early-phase trials & Confirmed \\
\hline Route of administration & $\begin{array}{l}\text { Parenteral route in early trial, oral route in } \\
\text { late trials }\end{array}$ & $\begin{array}{l}\text { Oral route is preferred, alternative route may } \\
\text { be considered }\end{array}$ \\
\hline Time of administration & $\begin{array}{l}\text { Either early in the attack or after an attack } \\
\text { is fully developed }\end{array}$ & $\begin{array}{l}\text { Early intake, or intake when pain is moderate } \\
\text { or severe are all acceptable options as long } \\
\text { as they are pre-specified in the protocol }\end{array}$ \\
\hline $\begin{array}{l}\text { Number of attacks treated } \\
\text { with the same treatment }\end{array}$ & One attack & Confirmed \\
\hline Rescue medication & $\begin{array}{l}\text { Any time after the first primary efficacy } \\
\text { time point }\end{array}$ & Confirmed \\
\hline Consistency of response & $\begin{array}{l}\text { Evaluated over five attacks with two pos- } \\
\text { sible approaches }\end{array}$ & $\begin{array}{l}\text { Evaluated over four attacks with three possi- } \\
\text { ble approaches }\end{array}$ \\
\hline \multicolumn{3}{|l|}{ Evaluation of results } \\
\hline Attack report diary & Use a simple report diary & Electronic diary \\
\hline Primary end-point(s) & $\begin{array}{l}\text { Percentage of patients pain-free within } 2 \\
\text { hours }\end{array}$ & $\begin{array}{l}\text { Two recommended: Percentage of patients } \\
\text { pain-free within } 2 \text { hours and the most } \\
\text { bothersome migraine associated symptom } \\
\text { as co-primary endpoint }\end{array}$ \\
\hline Secondary endpoints & $\begin{array}{l}\text { Relapse } \\
\text { Sustained pain freedom }\end{array}$ & $\begin{array}{l}\text { Confirmed } \\
\text { Confirmed (preferred to relapse) }\end{array}$ \\
\hline
\end{tabular}


Table 4. Continued.

\begin{tabular}{|c|c|c|}
\hline & 2012 & 2018 \\
\hline & Total migraine freedom & Confirmed \\
\hline & Intensity of headache & Confirmed (VAS and NRS also recommended) \\
\hline & Headache relief & Confirmed \\
\hline & Time to meaningful relief & Confirmed \\
\hline & Time to pain freedom & Confirmed \\
\hline & Duration of attacks not recommended & Confirmed \\
\hline & Rescue medication & Confirmed \\
\hline & Global evaluation & Confirmed \\
\hline & Global impact & Confirmed $(24 \mathrm{hMSQ}$ oL and MSEP are \\
\hline & Migraine associated symptoms & recommended) \\
\hline & Adverse events & Confirmed \\
\hline & & Confirmed \\
\hline & & New endpoints added: \\
\hline & & $\begin{array}{l}\text { Time between onset of headache and intake of } \\
\text { treatment }\end{array}$ \\
\hline & & Treatment preference \\
\hline & & Blinding assessment \\
\hline & & Treatment of relapse \\
\hline \multicolumn{3}{|l|}{ Statistics } \\
\hline Sample size calculations & Use primary efficacy measure & $\begin{array}{l}\text { Adopt the hierarchy of endpoints one would } \\
\text { need to consider the appropriateness of an } \\
\text { adjustment for multiple comparisons if } \\
\text { there is more than one primary endpoint }\end{array}$ \\
\hline Confidence intervals & Recommended & No changes \\
\hline
\end{tabular}

least a moderate intensity, but also early intake or intake when the attack has fully developed are acceptable as timings for testing drug efficacy provided that they are prospectively indicated in the protocol. The assessment of consistency of response should be evaluated over four attacks, ideally after an initial 1-month double-blind phase, where the patients treat the first attack with either the active drug or placebo, followed by a 1- or a 2-month open-label phase, where the patient treats $\geq 3$ attacks with the active drug. Three possible approaches for this latter period are proposed in the 4th edition. As regards the route of administration, the 4th edition suggests the oral formulation whenever possible, but considers other possible routes in specific circumstances.

Evaluation of results. This section has provided greater clarity and incisiveness as regards the primary and secondary endpoints that clinical trials should use. Painfree at 2 hours is still recommended as the primary measure of efficacy, but the new Guidelines recommend using the most bothersome symptom as a co-primary endpoint. This symptom must be defined prospectively, prior to randomization. The other migraine-associated symptoms should be captured as secondary endpoints. Sustained pain freedom is preferred to relapse rate as it is considered more scientifically robust because it integrates initial response, use of rescue medication and recurrence. Sustained relief is no longer recommended.

The intensity of headache should be measured with the ordinal four-point scale at different timepoints. The Visual Analogue Scale or an 11-point numerical rating scale may also be used as an alternative or in association. Headache relief is maintained as a secondary endpoint, in analogy to the time to meaningful relief and time to pain freedom, which can now be more easily and reliably captured with electronic diaries. Time to pain freedom is defined as a more exact and less subjective measure than time to meaningful relief. Important new evaluation instruments of disability are introduced in the Global Impact section. These are the Functional Impairment Scale (FIS) and the Migraine Physical Function Impact Diary (MPFID).

A new endpoint is represented by the time between onset of headache and intake of study drug, which is important in trials investigating the efficacy of early treatment. Another new endpoint is the blinding assessment, which can be evaluated using questionnaires for the evaluation of correct and incorrect guesses.

Statistics. In the 4th edition, the hierarchy of endpoints assumes a fundamental role. Furthermore, different statistical methodologies are suggested depending on 
the study approach, along with indications for calculating the appropriate sample size.

\section{Discussion}

In this paper, we reviewed the adherence to the 3rd edition of Guidelines for controlled trials of drugs for the acute treatment of migraine, carrying out a comparison with the current guidelines (4th edition, published in 2019) in order to make the reader aware of the changes introduced and familiar with the rationale behind them.

\section{Adherence to Guidelines}

When we assessed the different sections of the Guidelines, we observed a satisfactory level of adherence as regards patient selection. We observed, however, that the number of studies that followed the trial design recommendations, namely the placebo control, was less than $50 \%$. The same was true when we assessed the section on the evaluation of results. We found that only $45 \%$ of the RDB trials used the recommended primary efficacy measure. In addition, we observed quite a wide variability in the secondary/ other efficacy measures adopted in the different trials. These findings may find an explanation in the fact that, in the period under consideration (2012-2018), the number of new molecules for the acute treatment of migraine was quite limited (see Table 3 ). Thus, a considerable number of trials focused on substances whose efficacy had already been proven in pivotal studies, which may have prompted the opportunity to focus on different endpoints to prove additional benefits or indications for the intervention. For instance, 14 trials focused on new delivery methods or doses of known anti-migraine drugs. In this frame, it is understandable why more than $50 \%$ of the trials were not placebo controlled, but rather used a comparative design. It is also worth noting that the number of controlled trials published in the 2012-2018 period was much lower than in the previous analysis (2002-2008) (5), when 145 trials were eligible for review. Indeed, a recent review of studies on the acute treatment of headache showed that the number of publications decreased after 2010 (8). In the post-triptan era, there has been a progressive increase in clinical trials on preventive treatment in contrast to trials for the acute treatment of migraine attacks.

The current analysis of adherence to the 3rd edition of IHS Guidelines for the acute treatment of migraine shows that there has not been a substantial improvement in the compliance with the IHS Guidelines over the years, as we detected a reduction in the percentage of trials using a placebo-controlled design together with a slight increase in the percentage of trials that adopted the recommended primary outcome measure. This last observation is somewhat surprising considering that a recent review on the compliance with the primary endpoints for the acute treatment of headache recommended by subsequent editions of the IHS Guidelines over the period 1991-2013 showed that the adherence to the 2-hour headache-free endpoint progressively increased over time: $36.4 \%$ in $1991,39.6 \%$ in $2000-2002,83.3 \%$ in 2013 (8). It must be, however, noted that the figures reported in the above review also include studies targeting other primary headaches besides migraine; furthermore, headache freedom was assessed at timings different from 2 hours, which makes the findings difficult to compare with our analysis.

Altogether, these considerations represent a strong motivation for the 4th edition of the Guidelines. These were developed using a new, interactive methodology that involved all the relevant stakeholders, from the wider IHS membership to representatives of the pharmaceutical industry, also including patients' representatives and representative of regulatory bodies (12). This adapted and more inclusive methodology will hopefully ensure a more strict and capillary adoption of the recommendations, thus ultimately reinforcing the scientific strength of the trials dealing with antimigraine drugs.

\section{Changes between editions}

The most important updates were applied to the sections dealing with trial design and evaluation of results, the areas where we observed a low compliance regarding the previous edition. Indeed, we found that most clinical trials on the acute treatment of migraine used the IHS diagnostic criteria $(87.5 \%)$, but the general recommendations regarding randomization, double-blind and placebo-control, or the primary outcome measure were followed in less than $50 \%$ of trials. Of note, several trials incorrectly used "headache relief" as the primary endpoint. The recommended secondary efficacy variables were used in a quite erratic way, with "sustained pain-free" adopted in six trials $(25 \%)$, while a modified and less rigorous version of this efficacy measure (headache relief at $24 \mathrm{~h}$ instead of $48 \mathrm{~h}$ ) was used in nine RDB trials.

Investigators should be aware of the importance of following these updated guidelines for ensuring highquality research in headache. If not, the results of their trials might not be comparable, or reproducible, thus increasing the risk that new substances that may have a role in the acute treatment of migraine fail to be approved by regulatory authorities due to 
methodological weakness. Diagnosis of migraine should be unambiguously based on the ICHD-III criteria. General design recommendations, such as randomization, double-blind and placebo-controlled features, should be mandatory. Block randomization is recommended, and stratification is important for variables that have demonstrated an impact on the primary study outcome. RCTs in acute migraine should follow the principle of intention-to-treat when the primary outcome is a variable that measures a change from baseline to the end of the study. For evaluating consistency of response a new approach is proposed, treating a greater number of attacks with the active drug.

Concerning the evaluation of results, the primary endpoint "pain-free at 2 hours" continues to be crucial, but the 4th edition of the Guidelines suggests the use of co-primary endpoint. For many patients, accompanying symptoms may be as disabling or, in some cases, more disabling than pain (10). Thus, it seems important to introduce a new concept that better reflects this reality.

Similarly, of the decision to drop "headache relief" as a primary endpoint is motivated by the fact that it does not reflect what patients actually consider important, and it is associated with a higher placebo response rate than pain freedom at 2 hours (9). Concerning the secondary endpoints, some are still recommended, such as "sustained pain freedom", "time to pain freedom", "rescue medication at 2 hours", "global evaluation of medication" and "global impact measures"; others, such as "sustained relief", were dropped and others, like "time to pain freedom" were modified to reduce subjectivity. Functional disability scales as well as global evaluation of medication are currently recommended. In addition, non-clinical endpoints (patientrelated outcome measures, or PROMs) are receiving growing attention and they must be taken into account for future interventions (11).

The analysis and comparison performed in this study have some limitations. First, the scoring system is based on a very simplified version of the 3 rd edition guidelines. This system has been adopted because it is easy to use, intuitive, and it ensures consistency across analyses. However, it does not allow an in-depth individual comparison among the reasons for lack of adherence.
Second, fewer studies have been evaluated as the quantity of clinical trials on the acute treatment of migraine has decreased and fewer studies have been evaluated. This is a direct reflection of the focus of interest, investment and clinical development in migraine in the years analyzed, which were characterized by a more marked interest in developing and testing preventive substances.

Adherence to guidelines is mandatory to ensure the highest possible quality of trials in terms of efficacy and safety evaluation and to provide comparable data for meta-analyses. The IHS Clinical Trials Subcommittee has striven hard to optimize the latest edition of the Guidelines for clinical trials on the acute treatment of migraine and recommends their adoption in future RCTs (12). Updating these guidelines has indeed been a complex process that has taken into consideration the expertise of the Working Group members, the point of view of relevant stakeholders and the data published in the literature. The present analysis was conducted to address the last point, in order to inform the extensors of the Guidelines on the critical issues of the previous guidelines. We believe that the publication of the results of this analysis, together with the reiteration of the importance of following the Guidelines, will facilitate their adoption and implementation. It is expected that, from now on, only trials that satisfy these recommendations will be accepted for publication in top-level scientific journals as pivotal studies. This is important for ensuring excellence in measuring efficacy, safety, and tolerability of treatments, and ultimately for benefitting our patients.

\section{Conclusions}

Although the quality of clinical trials in migraine is generally high and has led to substantial advances in the pharmacological treatment of the disease, adherence to the Guidelines is not yet satisfactory. Thus, there is still a need and room for improvement and we expect that the new updated and improved edition of IHS Guidelines for controlled trials of acute treatment of migraine attacks in adults will provide the appropriate framework for researchers to achieve the highest possible quality of research and provide the best treatment options for our patients.

\section{Article highlights}

- Adherence to previous Guidelines has been suboptimal.

- The 4th edition of the Guidelines has introduced important updates in trial design and evaluation of results.

- These changes coincide with the sections that were least adhered to in the previous edition of the Guidelines. 


\section{Author contributions}

AA, CT and PP-R have made substantial contributions to the conception and design of the paper. AA has done the analysis and first draft of the paper.

PP-R, CT, CD, SDS have critically revised and finally approved the version to be published.

\section{Declaration of conflicting interests}

The authors declared the following potential conflicts of interest with respect to the research, authorship, and/or publication of this article: AA has no potential conflicts of interest with respect to the research, authorship, and/or publication of this article.

In the last 3 years, HCD received honoraria for participation in clinical trials, contribution to advisory boards or oral presentations from: Allergan, Amgen, Electrocore, Ipsen Pharma, Lilly, Novartis, Teva and Weber \& Weber. Financial support for research projects was provided by Allergan, Electrocore, and Pfizer. Headache research at the Department of Neurology in Essen is supported by the German Research Council (DFG), the German Ministry of Education and Research (BMBF) and the European Union. H.C. Diener has no ownership interest and does not own stocks of any pharmaceutical company. HCD serves on the editorial boards of Cephalalgia and Lancet Neurology. HCD chairs the Clinical Guidelines Committee of the German Society of Neurology and is a member of the Clinical Trials Committee of the IHS.

In the last 3 years, CT has received honoraria for participation in clinical trials, contribution to advisory boards or scientific presentations from Allergan, Electrocore, Eli-Lilly, Novartis, Teva and Medscape. CT has received independent support from the Italian Ministry of Health, Italian Ministry of Research and European Community. CT has no ownership interest and does not own stocks of any pharmaceutical company. CT serves as Chief Section Editor of Frontiers in Neurology - Section Headache Medicine and Facial Pain and on the editorial board of Journal of Headache and Pain. CT has been chairman of the Clinical Trials Committee of the IHS.

In the last 3 years, SDS has received honoraria for consultancy or participation to advisory panels from Alder Biopharmaceuticals; Allergan, Inc.; Amgen; Avanir Pharmaceuticals, Inc.; Curelator, Inc.; Dr. Reddy's Laboratories; eNeura Inc.; electroCore Medical, LLC; Lilly USA, LLC; Medscape, LLC.; NINDS; Supernus Pharmaceuticals, Inc.; Teva Pharmaceuticals; Theranica; and Trigemina, Inc.

In the last 3 years, PP-R received honoraria for participation in clinical trials, contribution to advisory boards or oral presentations from: Allergan, Almirall, Amgen, Chiesi, Electrocore, Eli Lilly, Medscape, Novartis, Teva. Financial support for research projects was provided by Allergan. Headache research is supported by la Caixa Foundation, MINECO, AGAUR, Fundació La Marató TV3, Instituto Investigación Carlos III, Migraine Research Foundation, Mutual Medica, PERIS. PP-R has no ownership interest and does not own stocks of any pharmaceutical company. PP-R serves on the editorial boards of Frontiers in Neurology - Section Headache Medicine and Facial Pain, The Journal of Headache and Pain, and is the Chief Editor for Revista de Neurologia - Headache Section. PP-R is a member of Clinical Trials Committee of the IHS. She has been the editor of the 3 Diagnostic and Treatment Guidelines for Headache of the Spanish Neurological Society.

\section{Funding}

The authors received no financial support for the research, authorship, and/or publication of this article.

\section{ORCID iDs}

Alicia Alpuente (D) https://orcid.org/0000-0001-5296-9401

Cristina Tassorelli (D) https://orcid.org/0000-0003-1513-2113

Stephen D Silberstein (D) https://orcid.org/0000-0001-94675567

\section{References}

1. Tfelt-Hansen P, Block G, Dahlof C, et al. Guidelines for controlled trials of drugs in migraine. First edition. Cephalalgia 2000; 20: 765-786.

2. Tfelt-Hansen P, Block G, Dahlof C, et al. Guidelines for controlled trials of drugs in migraine: Second edition. Cephalalgia 2000; 20: 765-786.

3. Tfelt-Hansen $\mathrm{P}$, Pascual $\mathrm{J}$, Ramadan $\mathrm{N}$, et al. Guidelines for controlled trials of drugs in migraine: Third edition. A guide for investigators. Cephalalgia 2012; 32: 6-38.

4. US Food and Drug Administration, Center for Drug Evaluation and Research. Migraine: Developing drugs for acute treatment guidance for industry, https://www. fda.gov/downloads/drugs/guidances/ucm419465.pdf (February 2018)..

5. Hougaard A and Tfelt-Hansen P. Are the current IHS guidelines for migraine drug trials being followed? $J$ Headache Pain 2010; 11: 457-468.

6. Deen M, Martinelli D, Pijpers J, et al. Adherence to the 2008 IHS guidelines for controlled trials of drugs for the preventive treatment of chronic migraine in adults. Cephalalgia 2019; 39: 1058-1066.

7. Headache Classification Committee of the International Headache Society (IHS). The International Classification of Headache Disorders, 3rd edition (ICHD-3). Cephalalgia 2018; 38: 1-211.

8. García-Azorin D, Yamani N, Messina LM, et al. A PRISMA-compliant systematic review of the endpoints employed to evaluate symptomatic treatments for primary headaches. J Headache Pain 2018; 19: 90.

9. Macedo A, Farré M and Baños JE. A meta-analysis of the placebo response in acute migraine and how this response may be influenced by some of the characteristics of clinical trials. Eur J Clin Pharmacol 2006; 62: 161-172.

10. Silberstein SD. Migraine symptoms: Results of a survey of self-reported migraineurs. Headache 1995; 35: 387-396. 
11. Susan Marshall, Haywood K and Fitzpatrick R. Impact of patient-reported outcome measures on routine practice: A structured review. J Eval Clin Pract 2005; 12: 559-568.

12. Diener HC, Tassorelli C, Dodick DW, et al. Guidelines of the International Headache Society for controlled trials of acute treatment of migraine attacks in adults: Fourth edition. Cephalalgia 2019; 39: 687-710.

13. Spierings ELH, Brandes JL, Kudrow DB, et al. Randomized, double-blind, placebo-controlled, parallel-group, multi-center study of the safety and efficacy of ADAM zolmitriptan for the acute treatment of migraine. Cephalalgia 2018; 38: 215-224.

14. Singhal AB, Maas MB, Goldstein JN, et al. High-flow oxygen therapy for treatment of acute migraine: A randomized crossover trial. Cephalalgia 2017; 37: 730-736.

15. Voss T, Lipton RB, Dodick DW, et al. A phase IIb randomized, double-blind, placebo-controlled trial of ubrogepant for the acute treatment of migraine. Cephalalgia 2016; 36: 887-898.

16. Tepper SJ, Cady RK, Silberstein S, et al. AVP-825 breath-powered intranasal delivery system containing 22 $\mathrm{mg}$ sumatriptan powder vs. $100 \mathrm{mg}$ oral sumatriptan in the acute treatment of migraines (The COMPASS Study): A comparative randomized clinical trial across multiple attacks. Headache 2015; 55: 621-635.

17. Marcus R, Goadsby PJ, Dodick D, et al. BMS-927711 for the acute treatment of migraine: A double-blind, randomized, placebo controlled, dose-ranging trial. Cephalalgia 2014; 34: 114-125.

18. Landy S, Munjal S, Brand-Schieber E, et al. Efficacy and safety of DFN-11 (sumatriptan injection, $3 \mathrm{mg}$ ) in adults with episodic migraine: A multicenter, randomized, double-blind, placebo-controlled study. $J$ Headache Pain 2018; 19: 69.

19. Lipton RB, Munjal S, Brand-Schieber E, et al. DFN-02 (sumatriptan $10 \mathrm{mg}$ with a permeation enhancer) nasal spray vs. placebo in the acute treatment of migraine: A double-blind, placebo-controlled study. Headache 2018; 58: 676-687.

20. Karacabey S, Sanri E, Yalcinli S, et al. Which is more effective for the treatment of acute migraine attack: Dexketoprofen, ibuprofen or metoclopramide? Pakistan J Med Sci 2018; 34: 418-423.

21. Martins LB, Rodrigues AMDS, Rodrigues DF, et al. Double-blind placebo-controlled randomized clinical trial of ginger (Zingiber officinale Rosc.) addition in migraine acute treatment. Cephalalgia 2019; 39: 68-76.

22. Amiri H, Ghodrati N, Nikuyeh M, et al. Comparison of granisetron and metoclopramide in the treatment of pain and emesis in migraine patients: A randomized controlled trial study. Turkish J Emerg Med 2017; 17: 61-64.

23. Rad RE, Ghaffari F, Fotokian Z, et al. The effectiveness of ibuprofen and lorazepam combination therapy in treating the symptoms of acute migraine: A randomized clinical trial. Electron Physician 2017; 9: 3912-3917.

24. Cady RK, Munjal S, Cady RJ, et al. Randomized, double-blind, crossover study comparing DFN-11 injection (3 mg subcutaneous sumatriptan) with $6 \mathrm{mg}$ subcutaneous sumatriptan for the treatment of rapidly escalating attacks of episodic migraine. $J$ Headache Pain 2017; 18: 17.

25. Rao AS, Gelaye B, Kurth T, et al. A randomized trial of ketorolac vs. sumatripan vs. placebo nasal spray (KSPN) for acute migraine. Headache 2016; 56: 331-340.

26. Ghaderibarmi F, Tavakkoli $\mathrm{N}$ and Togha $\mathrm{M}$. Intravenous valproate versus subcutaneous sumatriptan in acute migraine attack. Acta Med Iran 2015; 53: 633-636.

27. St. Cyr A, Chen A, Bradley KC, et al. Efficacy and tolerability of STOPAIN for a migraine attack. Front Neurol 2015; 6: 11.

28. Vanderpol J, Bishop B, Matharu M, et al. Therapeutic effect of intranasal evaporative cooling in patients with migraine: A pilot study. J Headache Pain 2015; 16: 5 .

29. Moshtaghion H, Heiranizadeh N, Rahimdel A, et al. The efficacy of propofol vs. subcutaneous sumatriptan for treatment of acute migraine headaches in the emergency department: A double-blinded clinical trial. Pain Pract 2015; 15: 701-705.

30. Zhang A, Jiang T, Luo Y, et al. Efficacy of intravenous propacetamol hydrochloride in the treatment of an acute attack of migraine. Eur J Intern Med 2014; 25: 629-632.

31. Mainardi F, Maggioni F, Pezzola D, et al. Dexketoprofen trometamol in the acute treatment of migraine attack: A phase II, randomized, double-blind, crossover, placebo-controlled, dose optimization study. J Pain 2014; 15: 388-394.

32. Turkcuer I, Serinken M, Eken C, et al. Intravenous paracetamol versus dexketoprofen in acute migraine attack in the emergency department: A randomised clinical trial. Emerg Med J 2014; 31: 182-185.

33. Allais G, Rolando S, Schiapparelli P, et al. Frovatriptan plus dexketoprofen in the treatment of menstrually related migraine: An open study. Neurol Sci 2013; 34: 179-181.

34. Mehdi M, Farhad G, Alireza ME, et al. Comparison between the efficacy of ginger and sumatriptan in the ablative treatment of the common migraine. Phytother Res 2014; 28: 412-415.

35. Öztürk V, Ertaş M, Baykan B, et al. Efficacy and safety of 400 and $800 \mathrm{mg}$ etodolac vs. $1000 \mathrm{mg}$ paracetamol in acute treatment of migraine: A randomized, doubleblind, crossover, multicenter, Phase III clinical trial. Pain Pract 2013; 13: 191-197.

36. Friedman BW, Cabral L, Adewunmi V, et al. Diphenhydramine as adjuvant therapy for acute migraine: An emergency department-based randomized clinical trial. Ann Emerg Med 2016; 67: 32-393. 


\section{DuEPublico}

Duisburg-Essen Publications online
DESISBEN R G

offen im Denken

Ub $\mid \begin{gathered}\text { universitäts } \\ \text { bibliothek }\end{gathered}$

This text is made available via DuEPublico, the institutional repository of the University of Duisburg-Essen. This version may eventually differ from another version distributed by a commercial publisher.

DOI: $\quad 10.1177 / 0333102420906843$

URN: urn:nbn:de:hbz:464-20210702-105312-8

This publication is with permission of the rights owner freely accessible due to an Alliance licence and a national licence (funded by the DFG, German Research Foundation) respectively.

(C) International Headache Society 2020. All rights reserved. 